\title{
The Nameless Shadowy Vortex: The Artist of Transition
}

\section{Paul Carter}

The nature of infinity is this! That every thing, has its Own Vortex; and when once a traveller thro' Eternity, Has pass'd that Vortex, he percieves it roll backward behind His path, into a globe itselfinfolding: like a sun:

Or like a moon, or like a universe of starry majesty ...

William Blake ${ }^{1}$

'The Nameless Shadowy Vortex' was originally an improvisation performed at Artists' Week at the 2012 Adelaide Festival. The essay presented here is a further vortex spinning off the materials presented on that occasion. The parts of the essay, and the internal associative logic shaping each part, imitate in some way Blake's notion of successive vortices spinning backwards down the lifepath one has taken. The linear conventions of (scholarly) publishing are entirely different, implying a simple progress step by step towards illumination. Blake, by contrast, understood the merits of poetic involvement; like De Quincey, he recognised the structure of ideation as turbulent, characterised by a constant feedback between presented elements and the shape of thoughts to come. It is in this spirit that the brief for the artist of the transition is sketched. The endnotes appended to the essay reflect the character of the vortex: they spread out to embrace an unusually diverse range of literary references; at the same time, they draw these diverse universes of research rather abruptly into the path of the present whirling meditation. Some readers may find this style of allusion disconcerting: in its defence it can be said that further development of what Paul Valery might call this poetic 'system' would surely reveal yet other 
associative universes underpinning the logic of this one. If this defence fails, the essay yet remains a faithful 'vortex street' drawn through the field of interests that have stretched back a quarter of a century, and which here achieve a kind of poise or meeting place, even if it is temporary and likely to roll backward very shortly.

I

If there can be multiverses, why not multiworlds? Intuitively, at least, we know that the world we inhabit, often identified as the Earth, consists of a multitude of life worlds: individuals pass through the mass of life that swarms across its surface touching but the tiniest part of its collective vitality. In whose name, then, do we insist on its limits, its finitude? Territorially speaking, the earth has measurable boundaries and area: but the world would appear to be something different, 'one infinite plane', according to William Blake, 'and not as apparent/ To the weak traveller confin'd beneath moony shade.'2 From the context of this statement, a passage in the self-confessed 'Poem from immediate dictation', 'Milton', the weakness of the 'traveller' is imaginative. ${ }^{3}$ In his mythological allegories Blake narrates the present condition of 'Albion' as a descent of 'Eternity' into the realms of time and space, characterised by a progressive corruption of 'The heavenly light with which the world is illuminated ... at all times.' ${ }^{4}$ The decline is spiritual, marked by the rise of instrumental reason at the expense of poetic insight. ${ }^{5}$ To be confined 'beneath moony shade' is a sign of the traveller's 'spiritual condition'. As the descent into the shadowy realm of the literal, the mechanical, and the materialistic is a symptom of 'inner' self-betrayal, the remedy must also be 'spiritual', not in a minor, Christian sense ${ }^{6}$ but in the major sense of learning to become again 'the traveller thro' Eternity', an educative task Blake ascribes to the artist. The artist of the transition between this world and the next reverses the progressive enclosure of the soul, peeling back one onion skin of 'shade' after another towards the recovery of the eternal sun.

Shelley shared Blake's diagnosis of the malaise of contemporary English society - the world of the Industrial Revolution and the emergence of the 'second' British empire: 
PAUL CARTER: THE NAMELESS SHADOWY VORTEX

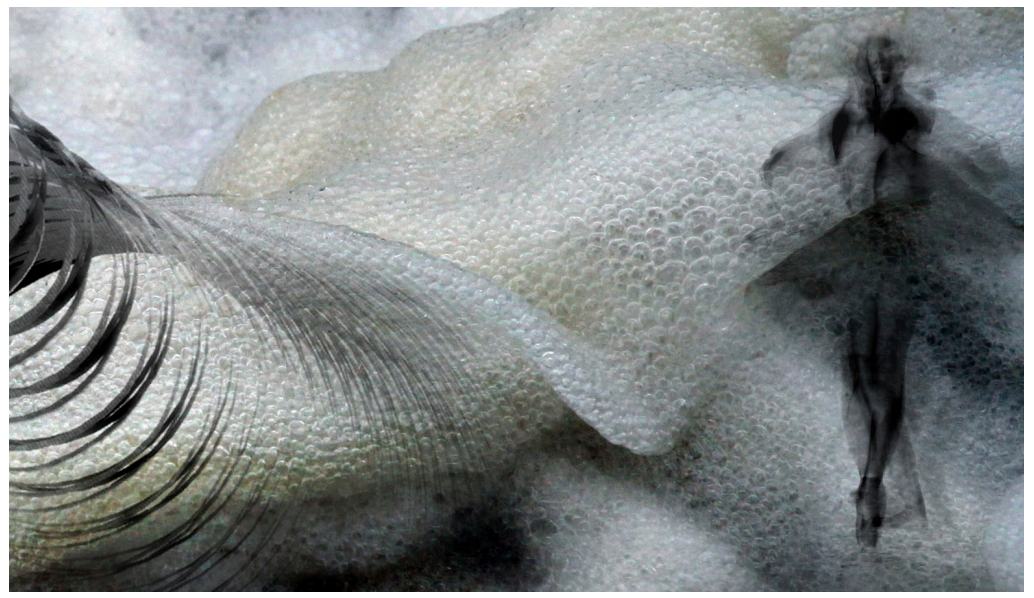

29 Edmund Carter

Performing Water, 2011 
We want the creative faculty to imagine that which we know; we want the generous impulse to act that which we imagine; we want the poetry of life: our calculations have outrun conception; we have eaten more than we can digest. The cultivation of those sciences which have enlarged the limits of the empire of man over the external world, has, for want of the poetical faculty, proportionally circumscribed those of the internal world; and man, having enslaved the elements, remains himself a slave. ${ }^{7}$

While Blake focuses on the vertical or psychological imprisonment of the soul and, even when moved by the horrors of the Caribbean slave colonies, transmutes historical events into a personal mythology of Paradise lost and regained, Shelley at least hints at the geographical impact of a want of 'creative faculty'. What are the implications, for example, for the white colonisation of Australia? If calculation - the endeavour of reducing Australia to a closed outline on a map-occurred at the expense of conception, what has been lost? What needs to be rediscovered? One could, in fact, begin the act of imaginative conceptualisation with a meditation on the name itself. A mythopoetic enquiry into the meaning of 'Australia' would discover a double orientation towards east and south, with a combined sense of further towards the origin. ${ }^{8}$ Translated into psychological terms, this is the realm of hope.

The occasion of the remarks that lie behind this essay was an invitation to address the theme of 'Heaven and Hell', which, in the context of the exhibitions and themes of Artists' Week at the 2012 Adelaide Festival, was, I thought, an opportunity to reflect on the role of creativity in imagining the world differently. Instead of adorning the present received world of natural history documentary, geopolitical fiction and satellite imagery, the artist might undertake to reconfigure the world. A new poetic geography, for example, might single out the artist of the transition from this world to the next. If, in the anthropocene period, the survival of thinking depends on thinking differently about our relationship with the physical environment, the application of the 'creative faculty' to the imagination of the world has a profound practical implication. Following Blake, it would temper the rhetoric of sustainability, 
whose vision of the future is a further decline of the present, with navigations of this world that enable us to imagine what we know: transition would involve a Blakean unfolding of the universal from the particular, an enlargement of the present to the boundaries of time and space. Such a development would do more than emancipate western slaves to the 'external world': it might harbour hope of wider reconciliation. I was struck by the words in artist Sandra Saunders's work, shown in the exhibition 'Deadly': 'when I die I will not go to your heaven above ... I will go to mother Earth. We will be one again. That's my Heaven.' ${ }^{9}$ Here, the inheritance of the Christian dualism taught (with disastrous spiritual and psychological consequences) at the mission is a temptation, it seems to me, to continue framing the good in terms of destructive oppositions: an otherwise inclusive indigenous conception of 'mother Earth' risks being essentialised, the heavens above traditionally integral to its constitution being subtracted as relics of colonial oppression. ${ }^{10}$

One way to materialise Blake's infinite plane is as a globe or sphere. In one sense closed (or finite), the sphere is also boundless and without starting point or finishing place. A spiralling trajectory across its surface might never return to its point of origin. However, from Blake's point of view, the distinction between the topology of the surface and the imagination of its progressive unfolding in the experience of the traveller through eternity is critical. For 'Objects such as the earth or the human heart, viewed from ordinary (fallen) perspectives, appear to be globes, folded in on themselves rather than infinite. ${ }^{11}$ In this case the role of the creative imagination is to unfold them, disclosing the infinity imprisoned with the finite - a task personified in the mythological figure of Los, 'the god of creative time who delivers man from the world of clock time, the poetic genius in man', ${ }^{12}$ and whose name, as befits the divine hero charged with reversing the corruption of the eternal sun in matter, is Latin Sol (Sun) back to front. ${ }^{13}$ And, borrowing from and adapting Descartes' vortical theory of cosmology, Blake imagines the reversal as a process of vortical formation: 'The nature of infinity is this! That every thing, has its/ Own Vortex; and when once a traveller thro Eternity,/ Has passd that Vortex, he percieves it roll backward 
behind/His path, into a globe itself infolding: like a sun:/ Or like a moon, or like a universe of starry majesty.'14

So let's begin here - with the 'moony shade'.

II

Scientists using the European Southern Observatory's 'Very Large Telescope' recently detected 'the telltale fingerprints of organic life on Earth'. 15 Using a technique called spectropolarimetry, they examined 'earthshine', the sunlight our planet reflects onto the moon, and which much more faintly the darkened portion of the new moon reflects back to earth. Biological material, including elements associated with life (oxygen, ozone, water) polarise the light they reflect. By analysing the different spectra of polarised light detectable in the moon's reflection of the earth's reflected sunlight, it was possible to show the presence of a 'red edge' caused by surface vegetation. ${ }^{16}$ In addition, 'the unique homochirality of biology', ${ }^{17}$ the fact that the molecules of organic matter turn in one direction rather than another, favouring 'one handedness over another', was another, more generalised sign of life on earth. ${ }^{18}$ Naturally, the interest of these findings was not that they revealed earthly 'biosignatures' but to provide a possible earthbound method for discovering signs of life on the surfaces of 'exosolar planets'.19 Although the reflected albedo of the earth is studied, the focus remains firmly on outer space and the worlds beyond our worlds. To be sure, there is a theoretical problem - how is 'biological' to be defined? - but the experiment is hardly solipsistic. At the very least spectropolarimetry brings us a step closer to detecting extraterrestrial life that has, like ours, a carbon-based organic chemistry.

However, the ingenuity of the experiment is intriguing. If, on the one hand, it displays a highly developed capacity for logical inference, it also illustrates a kind of blindspot, or perhaps tunnel vision, characteristic of scientific enquiry. True to the 'return to Paradise' ethos of scientific thought and practice, where the object is to 'correct appearances' with a view to establishing certain universal axioms, the study of doubly reflected light is itself entirely unreflective. Why, for example, focus so much attention on a curiosity about life on exosolar planets when the future of humanity depends on a better 
understanding of, and care for, the earth's biodiversity? Why privilege evidence of clouds and water found in light reflected from the barren plains of the moon over a better (in depth) understanding of our oceans? If the discoveries made with the Very Large Telescope are another triumph for instrumentation, computation and interpretation, they are also evidence for how profoundly our scientific culture dwells, operationally and metaphorically, in the 'moony shade'. In an earlier epoch, at least, it did not have to be this way. In Cosmos, his great popular history of the evolution of human knowledge about the world and the universe, Wilhelm von Humboldt resisted the split between calculation and conception diagnosed by Shelley. His enthusiasm for the tropics was scientific and aesthetic: 'There the depths of the earth and the vaults of heaven display all the richness of their forms and the variety of their phenomena', ${ }^{20}$ a declaration that implies a poetic, if not physical, connection and reciprocity between Heaven and Earth, above and below. However, just as Newton's Laws of Motion seemed to show that Descartes' cosmology of vortices was so much moonshine, so, nowadays, no one wins competitive research grants to develop a reflective science, let alone a spiritual one where 'the eye of man' might still view 'both the east \& west encompassing/ Its vortex; and the north \& south, with all their starry host'. ${ }^{21}$

The nature of the new cosmos, the one that discovers 'infinities' within the finitude of the human condition and maps these onto the common place, the world we share and where we aim to coexist, might begin with a reversal of perspective: instead of training a very large telescope on other planets and swimming among the 'starry host', it would consider how other worlds illuminate our own. It would stay with the enabling phenomenon of reflection and develop a reflective science, where the above illuminates what is below. The results of such an enquiry would not be a mirror image of positivist science - the simple exposure of another knowable region: it would need to factor in the shade as well as the moon, the darkness as well as the light. At this point a dark knowledge might start to emerge that marked a point of poetic departure from the neoplatonic genealogies of progressive spiritual decline and imaginative eclipse favoured by Blake and Swedenborg. 'Man turns away from God, just as the earth 
turns away from the sun; and when he turns away from the truths of wisdom, he is like the earth turned away from the sun at night; and when he turns away from the goods of love, he is like the earth turned away from the sun in winter.'22 Even if Swedenborg speaks figuratively here, he demonstrates a kind of poetic fundamentalism, a pseudo-scientific identification of the truth with the light that casts the shadow of night in the role of lack, loss and all 'the falsities of evil'. ${ }^{23}$ The point is not that Swedenborg ignores rotatory reality but that his poetic firmament has no place for the world we live in. After all, in poetic geography night does not follow day any more than the horizons of either can be fixed or eliminated. While half the world sleeps, or wishes to dream, half the world energetically, tropically, greets the returning light. The spherical temporality of coexistence that characterises the rondure of worldly life is not an evacuation of Love: on the contrary, it is the signature of Eros - where, as Stanley Rosen writes, if 'the present is like a place, then it must be a place that we are always in'. ${ }^{24}$

A feature of this reflective world is what might be called its temporal chirality. In contrast with other worldly visions of the soul's journey through eternity, a world where knowledge is self-knowledge and is in touch with the dark and its unconscious powers and depths identifies the 'after life' with the life 'aft', or in the wake of passage. The before is after, a temporal ambiguity evident in these simple English words, but this does not mean that future and past are interchangeable, that time can be reversed. Time exhibits chirality or handedness: it goes one way rather than the other. The condition of Blake's statement, 'Thus is the heaven a vortex passd already, and the earth/ A vortex not yet pass'd', being true is that the vortices revolve in one direction not another: there is a spin to time. Meteorologists studying atmospheric turbulence can sometimes see 'vortex streets' forming down wind of mountains that break the clouds' flow. So with our lives: reflectiveness is not a state of calm tranquility, it introduces the unreachable and suspends the traveller like a bacchant between the dancers before and after and whose hands she holds. It is the creative passage but for which the terra firma axioms of Newtonian science would never revolve out of the main stream and slowing down grow calm and mirror like. 
'His imagination felt itself struck by the representation of some ghosts who presented themselves to him and who so frightened him that, thinking he was walking down streets, he had to lean to his left side in order to be able to reach the place where he wanted to go, because he felt a great weakness on his right side, so that he could not hold himself upright. Because he was ashamed to walk in this way, he tried to straighten up, but he was buffeted by gusts that carried him off in a sort of whirlwind that spun him around three or four times on his left foot'. ${ }^{25}$ So in a dream René Descartes experienced the dizziness of the creative vortex. Why, once out of the vortex street traversed, in the rational light of waking, did he put these perturbations behind him, announcing a new reflective science that, paradoxically, treated the world as uncertain and contingent in comparison with the truth claims of the cogito? The vortices came back in Descartes' cosmology, of course, but as attempts to reconcile the continuity of systems with their evident change. ${ }^{26}$ Change happens when, for unknown reasons, an imbalance between centripetal and centrifugal forces occurs; but the bias of the hypothesis is towards a general, axiom-based theory of cosmological dynamics that produces an overall effect of self-sameness. If, as Leibniz wrote, 'It seems that there is some centre of the entire universe, and some general infinite vortex ..., then the vortex is hardly a figure of thought at all. ${ }^{27}$ Like Einstein's curved time-space, it simply is: the torsion of becoming wrapped into the lining of Being.

However, for our reflective scientist and poetic geographer, this does not mean that it is etheric, unavailable to our sensory equipment. On the contrary: the infinite vortex is everywhere impacting on the line of thought. The resemblance between external volutes and internal ones is constantly brought before us, as we travel between horizons: in the before and after of life's toils, we are like Swinburne's persona in The Triumph of Time: 'In the change of years, in the coil of things,/ In the clamour and rumour of life to be ...'28 Artists of the transition distinguish themselves from cartographers and photographers by their willingness to follow its arabesques to the (endless) end. In relation to turbulence, the vortex is the representation of change. It is the proof that ceaseless movement might have formal inclinations. The vortex is the image of transition. If 
turbulence marks the inaugural moment of non-reversibility or simply history, then the vortex is what happens or takes place. Eddies are a state where the future is continually announced; their inconstant motion actualises power. These claims emerge when we pay attention to the volume of the vortex, its height and depth, the wobbling negative form of the conical volume it builds up, like a wavering pot emerging on the potter's wheel. For the 'inside' of the vortex is also its 'outside', its topology proprioceptive in a sense, exhibiting handedness, containment and the infinite, a reversibility that Blake grasps where he writes, 'There is an Outside spread Without, \& an Outside spread Within/ Beyond the Outline of Identity both ways, which meet in One.'29

In the Phaedo Socrates' poetic geography locates humans not on the earth's surface, which he places amid the aether, but on its lower shore: 'we living inhabit the earth's hollow places'. ${ }^{30}$ Etymologically, chaos is a term cognate with hollow. The yawning gap, in whose opening Eros moves to shape and distribute matter, separates sky from earth. ${ }^{31}$ As the elements fly apart, the elemental traces of them migrate to their right places. These traces are, presumably, curvilinear, like the volume of the widening chasm. Pondering how it can be that the word caelum is applied to the earth (loca infera) and to the sky (loca supera), the Roman grammarian Varro guesses that a common quality was once ascribed to them. He notes the sky could have been called caelum either because it was caelatum, 'raised above the surface' or because it was celatum, hidden by night. ${ }^{32}$ Either way, to explain the paradox, Varro guesses that both terms derive from chaos, from which 'came choum and then cavum "hollow", and from this caelum "sky", since, as I have said, "this around and above, which holds in its embrace the earth," is the cavum coelum "hollow sky"' ${ }^{33}$ The same principle applies when the word is used of the earth: 'from cavum "hollow" come cavea "cavity" ... cavernae "caverns" etc.' The word cavum was also applied to the spectators' part of the theatre; it also meant 'stall, bird-cage, bee-hive'. ${ }^{34}$ The hollow is, in this sense, the place where the ground is materialised-where place spins into being, perhaps in the pirouette of two people approaching as if to meet. Knowledge of this place is dark knowledge: pursued, it leads to a geography of 
the underworld. Pythagoras is supposed to have held the view that Hades was none other than the reality that no one has ever seen and is without form. ${ }^{35} \mathrm{He}$ is also said to have arrived in Italy via a journey through the underworld, a story that has been linked to a year spirit Bear Cult - the hibernating bear is imagined descending each winter to the moist gloom of the underworld, and returning thence with strange wisdom. In any case, the point is that, contra Descartes, Pythagoras was a student of the formless hollow: he 'looked for instruction in the circling stars and circulating winds and spiralling eddies in the muddy currents of the Meander'. ${ }^{36}$ Unlike Swedenborg, Pythagoras saw value in the sun at night and the sun in winter.

Another personification of the bear may be the folk hero on which Homer's Odysseus is based. The name 'Odysseus' is cognate with Otis, meaning 'Big Ears', apparently with reference to the bear's ears; and Odysseus' seven-year imprisonment in the loca infera of the nymph Calypso's cave humanises another seasonal myth. The presiding deity of reflective knowledge is indeed Calypso, whose name means 'covered' or 'hidden' and is related to the Etruscan god of the dead and the underworld, Kalu, in turn associated with the root for the hidden, $k e l$ - cache - or Hel. ${ }^{37}$ The verb kalypto means to dissimulate or wrap up the meaning so that it shines through obscurely - a challenge to the reflective hermeneut - and, in their attitude towards the communication of knowledge, Calypso and Hermes are close kin. Both believe that 'Truth is the mirror, not what's in it or behind it, but the very mirroring process itself.' ${ }^{38}$ Environmentally, Calypso is associated with hollows of all kinds - with covering - cloud cover, canopies and roofs; she is the patron of what is concealed and lies behind or beneath the surface, which, ambiguously, she both protects and obliterates. She buries to resurrect, offering Odysseus immortality if he stays. The geographical location that corresponds best to Calypso's homeland is not a coastal grotto in Puglia but Australia, the continent that, from a northern mythopoetic perspective, lies constitutionally beyond the horizon in the underworld. It was poetic fate not botanical observation that caused Australia's most characteristic vegetation to be named by the newcomers eucalyptus, the well-covered. Had they not hoped to find a new home beneath 
its canopy, they would not have rued the failure of its pendent leaves to shade them from the burning sun.

III

The earth's albedo varies according to the reflectance properties of its different surfaces: water has low albedo, snow high; clouds reflect a middling amount of light. If you did not know that the earth is a partially cloud-covered body composed of land and sea, taking the different albedo readings at face value, you might imagine it as a mottled and discontinuous body, a patchwork of regions distinguished by their different reflective properties. A reflective planet looked at in this way would suggest an archipelago of environments. Such an effect would not be solely due to different reflectance levels: it would also be influenced by the sunlight's angle of incidence with the earth's surface. The earth's albedo starts to look archipelagic, or patchy at least, because of the earth's rondure: at any time some equatorial parts of the hemisphere facing the sun lie at nearly ninety degrees to the direction of the sun's light, the earth's curvature causing the angle of incidence to diminish thence in all directions. In any case, it is not too far-fetched to say that a reflective geography could derive some support for its different conception of the earth from modern astronomy. The object would not be to dispute the material structure of the earth but to indicate a world there that science ignores, an infinity wrapped up in the globe that emerges when the earth's topology is taken into account and the complexity of its phenomenological appearance granted status as a way of knowing, even navigating, the cosmos. Clouds, oceans and river systems display traces of complex, vortical modes of coming into being and dying away. The fractal complexity of their (self-) organisation, disregarded for the purposes of detecting biosignatures in outer space, are finger prints of a cosmos within, 'an Outside spread Within/ Beyond the Outline of Identity'.

A poetic geography, one that seeks to outline a new conception of the world, understands the earth as a relational figure: the algorithm of relationality, one might say, is its rondure, the fact that all parts connect to all parts, a multiplicity of horizons - Blake's 'the rising sun \& setting moon he 
views surrounding/ His corn-fields and his valleys of five hundred acres square' (to continue quoting from the passage on the 'Vortex' in 'Milton') 39 - co-existing with unity - 'the earth one infinite plane'. Local regions are related to one another through the mechanism of the vortex. The vortices of self-becoming not only hollow out places: they link these trembling volumes one to another. Blake's view of this indigenous creativity, able and willing to go on creating in the 'moony shade' may have been ambiguous. For the Romantic imagination, self-consciousness imitates cosmic genealogy: its dialectical vertigo recapitulates the Empedoclean dynamics of physical creation, poised between centrifugal Strife and centripetal Love. 'The nameless shadowy vortex' that seduces Los in The Four Zoas is an expression of the 'shadowy female', 'this material world, a fallen form of Vala'. 40 (Vala is Nature.) However, she is also 'the voice of the Darwinian world, the struggle for life ... in the vision of the birth of Jesus, she sees her future salvation, her apocatastasis'. ${ }^{41}$ Los 'is Poetry, the expression in this world of the creative Imagination'; he creates Golgonooza, the city of art. 'Los creates the lines of poet-prophets who destroy the kings. He is the spiritual revolutionist, whose son Orc is outward revolution.' ${ }^{2}$ In other words the vortex is not only a dramatic image of descent into the maelstrom of the material world - a trajectory that no artist can by-pass - it is also an image of resurrection, of evolutionary ascent. In Swedenborg's spiritual architecture angels ascend and descend by way of spiral staircases.

The vortex of The Four Zoas is shadowy because it seduces Los from his spiritual purpose, betraying him into the path of literal, sexual reproduction. But why is the vortex 'nameless'? Perhaps, as Blake's view of the vortex is ambiguous, we can imagine that the epithet is not applied negatively but in recognition of a dark potentiality, something we might call the creative region, a place always to the south and east of what can be named, possessed and mastered. Such an interpretation conjures up Giorgio Agamben's discussion of a pure power of saying that does not convey a general form of knowledge or law but:

acts in its own weakness ... That this potentiality finds its 
telos in weakness means that it does not simply remain suspended in infinite deferral; rather, turning back to itself, it fulfils and deactivates the very excess of signification over every signified, it extinguishes languages ... In this way, it bears witness to what, unexpressed and insignificant, remains in use forever near the word. ${ }^{43}$

Nearness, a constitution that is doubled or multiplied, that finds its being interstitially, in the relative movement of parts, is the affective or social dimension of vortical dwelling. The centri-petal/-fugal tension of the turning figure creates the distance essential for coexistence.

In a similar vein, Stanley Rosen argues that 'the present ... is produced by the erotic (or caring) production of a cosmos (or world)'. ${ }^{44}$ Thus, with reference to the 'present' as 'a place that we are always in', Rosen suggests that temporality originates in Heidegger's Sorge (care or concern) or Platonic Eros. ${ }^{45}$ That is, we can coexist because we are inclined towards one another-whirled together. In this erotic formulation of the whirling turba (Latin for 'crowd'), the 'present' becomes possible through 'being by or next to'. ${ }^{46} \mathrm{~A}$ 'rank-ordering' is involved. 'We produce the lived present, not as a synthesis of temporal points, but as the self-orientation of erotic striving. ${ }^{47}$ Eros in this formulation is an intentionality not directed towards this or that object, but generally: 'In Heideggerian jargon, it is the opening of the horizon of the world'. ${ }^{48}$ And Rosen explains that the 'opening' is 'neither the present, the past, nor the future [but] the founding of the presence as the atemporal condition that makes possible the articulation of past, present, and future'. ${ }^{49}$ Translated into political terms, the vortex of the place we are always in is a state of tremulous potentiality or teetering towards stability than cannot be legislated but must be taken on trust. Its constitution is inseparable from the conduct involved in its continuous production. Hence, Hannah Arendt explains the emergence of the public domain as a creative region:

[In $\mathrm{t}$ ] he venture into the public realm ... one exposes oneself to the light of the public ... Speaking is also a form of action ... we start something. We weave our strand 
into a network of relations ... this venture is only possible when there is trust in people. A trust-which is difficult to formulate but fundamental - in what is human in all people. ${ }^{50}$

In this new world of becoming at that place, the pastoral image of Paradise - self-contained, changeless and shadowless - which finds its mechanical counterpart in the internally consistent movements of the clock-is replaced by the continuous production of relations through the vortex. Hesiod located 'the islands of the blessed' 'near the ocean's deep swirl', 51 a mighty whirlpool which has its Norse counterpart in the story of the origin of the maelstrom (mill stream): to explain the precession of the equinoxes, it was supposed that the original earth was composed of two hemispheres (or millstones) that turned in opposite directions on a vertical spindle. However, when the millstones were wickedly stolen and Amlodi, the mythological original of Shakespeare's Hamlet, forced the thieves to give them up, the millstones dropped into the sea, a whirlpool forming where water gushed through the spindle hole. 'The unhinging of the Mill is caused by the shifting of the world axis', ${ }^{52}$ and, as the Shakespearean sequel indicates, it raises the question of how disorder will be righted. The point is that creative regions are likely to be found in the neighbourhood of turbulence. They give credence to the idea that 'a theory of chaos and ordered turbulence' is not only plausible in the physical sciences but might be a core component of the political systems associated with the poetic geography of the archipelago. However, to advance this theory, 'chaos' would have to retrieve its ancient Greek meaning, of fertile opening, multiplying hollow, producer of change. For the vortex is not a fixed location in space and time but rather the event of space and time fusing, a process that throws off one vortex after another, before and aft.

In relational geography a new kind of time is imagined that involves us, carries us up in its eddies and transports us from one place to another. But what counts is the pre-creation of the new, stable vortex, the gathering process, the preceding instability, the initial weakness of the system that allows teetering to occur. Toiling across the central plains of Victoria during 
drought, the naturalist Thomas Belt noticed the phenomenon known locally as the 'willy-willy':

it was seen that as soon as one was formed, the air immediately next the heated soil, which was before motionless, or quivering as over a furnace, was moving in all directions towards the apex of the dust-column. As these currents approached the whirlwind, they quickened and carried with them loose dust and leaves into the spiral whirl. ${ }^{53}$

Belt concluded, against the received view, that hot air did not always immediately rise; instead it might form a heated stratum immediately above the ground 'in a state of unstable equilibrium': 'This continued until the heated stratum was able, at some point where the ground favoured a comparatively greater accumulation of heat, to break through the overlying strata of air, and force its way upwards. 54 The force necessary to make this sudden, violent passage, to drive the air upwards, was in embryonic form the same that drove the cyclone's violent revolution. Here is a physical observation that illuminates the distinction between creative and destructive chaos, between two phases of the phenomenon. It suggests a communicated tension or readiness; a neighbourhood of watchfulness.

Transposed to the human domain, the prechaotic state of unstable equilibrium recalls Freud's description of the agitation of the preconscious as it wanders this way and that looking for the right associative path. In my book The Lie of the Land, a book itself organised vortically allowing historical events apparently remote in time and space to be related poetically, according to common compositional principles, some cultural instances are given of this disposition to entertain turbulence as a precursor of transition to a new and more complex order. Belt's discussion of winds naturally recalls Roger Ascham's extraordinary description of the flakes of snow, which, although falling, sometime ran round about in a compass - an observation that should remind the new toxophilist that he always fired his arrow into a turbulent medium. ${ }^{55}$ It also recalls those ambiguous spells in Central Australia where, as one Arrernte rainmaker told the anthropologist 
T.G.H. Strehlow, 'Our clouds are still wandering about: they are going north, south, east, and west.' ${ }^{6}$ From the point of view of the Positivist storm these uneventful phases signify drought; from another perspective they are periods of creative vagrancy when a variety of possibilities open up and, leaving the high road of linear reason, we entertain the other compass points of poeisis or, better, give up horizons to concentrate on the great cracks where the heated air shimmers and which, from the perspective of relationality, are the joins of an archipelago of plates.

It's obvious that in this new reflective world the ocean assumes a new importance. It is the relating medium par excellence, the incubator of nature's most spectacular vortices; and, in fact, considered as a total body, comprising the globe's entire humid system, it can be said to replace land-based conceptions of the earth entirely. Describing an integrated system of flux, Michel Serres refers to a 'living syrrhesis' that:

combines sea and islands. In a completely new sense, the organism is synchronous for meanings and directions, for the continuous and discontinuous, for the local and the global; it combines memory, invariance, plan, message, loss, redundancy, and so forth. It is old, mortal, and the transmitter of a new cycle. The organism is fixed on top of a temporal converter - no, it is a converter of time. This is perhaps why it is able to learn about systems differentiated by their individual time: the world, fire, and signs. ${ }^{57}$

In terms of a poetic geography, this can be understood as a new kind of archipelago. In his poetic history of the Mediterranean, Matvejevic writes: 'One trait most islands share is the anticipation of things to come: even the smallest looks forward to the next boat, to the news it will bring, to some scene, some event.' ${ }^{58}$ But this might not be a peculiarity confined to individual islands: it might define the engine of desire that orders the archipelago as a whole, so that, following Serres, it does not represent a creative region so much as produce it, the intervals between islands being converters of time and space, synchronous and polyhedral-just as the earth considered as a sphere is composed wholly of horizons. 
To discover an archipelago that corresponded to this new world, it is necessary, though, to sail beyond the Pillars of Hercules - to the West Indies, of course, which Edouardo Glissant has reimagined so powerfully - but also, with our further east and south bias in mind, to the East Indies. A typology or archipelagos is outside the scope of this essay. It would begin, though, with a contrast between the musically organised and choreographed Cyclades and their Mediterranean antithesis, the Sporades, which seem to lie at the limits of what can be identified as a region of common interests. Entering the Atlantic, it would turn northwards first, steering away from the maelstrom into the Baltic, where it would discover that there exists in Finnish the word 'Saaristoinen' meaning 'an area with many archipelagos'. ${ }^{59}$ In Finnish archipelago consciousness the islomane evoked by Laurence Durrell, 60 who is free of any desire for other places, is unimaginable: 'close connection with the sea is the minimum condition of an archipelago' - 'I know myself that you must have the feeling that you can take a rowboat and row even to China from your own seashore, it is not necessary to see the water, but you must know that it is there, and you should preferably also be able to see it.' 61 Which fantasy leads directly to the early European conceptions of what Marco Polo referred to with a characteristic confusion of poetic conception with scientific calculation when he reported 'Beyond the China Sea there are 7,448 islands. No one has ever seen them all.' 62

Humboldt speculated that the universe consisted of 'innumerable systems scattered like islands through the immensity of space, and each composed of a sun and a moon'. ${ }^{63}$ In that case their earthly counterpart is the combined island swarms of the Indonesian and Philippine archipelagos. There is a chapter to be written about the distinctive style Portuguese cartographers used to represent this multitude without edge. Here one feature can be mentioned as typical of the 'opening to the horizon' that these non-Mediterranean arrangements inspired: the representation of the islands as open figures composed of passages. In the Homem chart, for example, it is harbours, river entrances and other locations of passage that are marked. Without continuous coastlines to differentiate land masses from navigational channels, it is a 
genuine syrrhesis that is depicted, where islands and ocean interpenetrate, and the principle of relationality subsumes land/water distinctions to produce a counter-intuitive outcome: the proliferation of limitless connections. It would be interesting (and it is overdue) to relate Australia's coming into being from this direction: from a south-east Asian, archipelagic sense of place, Australia might be conceived as the extension of the archipelago, not a territorial calculation to be bounded and separated but as an endless enlargement of the region of care. Instead of starting in 1770 or 1788 , it would enjoy an archipelagic temporality, infolded in the 'present' that becomes possible through 'being by or next to'.

\section{IV}

The artist of the transition helps us to navigate the earth so that we can imagine the world we already know. But what skills are needed to assume this role? Is the cartographer of the new cosmos a kind of geographical cybernaut, negotiating the whirlpools caused by the constantly forming and reforming relational state of things? Or a psychopompos of the surface, leading us to an underworld that belongs entirely to the world of light, despite the fact that, in the European myth, it lay in darkness until its discovery? One thing is fairly obvious: our companion will have to be a diver. This is not the place to attempt a cultural history of diving, but, if we did, it would be a relatively short one. In comparison with the amphibious focus of life in non-European, archipelagic communities, life in the European peninsula has traditionally been landbound. Philosophies of standing predominate and coastal and offshore environments are regarded as foreign to social and political stability. Even swimming seems to have been a relatively recent interest. Exceptionally, Theseus dives to the bottom of the sea ${ }^{64}$ but, generally, the above and the below, and the transition between these, which Heraclitus famously regarded as two aspects of each other, have been interpreted metaphorically, in terms of intellectual aspiration. Instead of diving, most scenarios of transition describe falling. In fact, blackout or syncope is almost a signature of the second birth needed to discover one's vocation.

In this context the significance of the dive in initiating us 
ART IN THE GLOBAL PRESENT

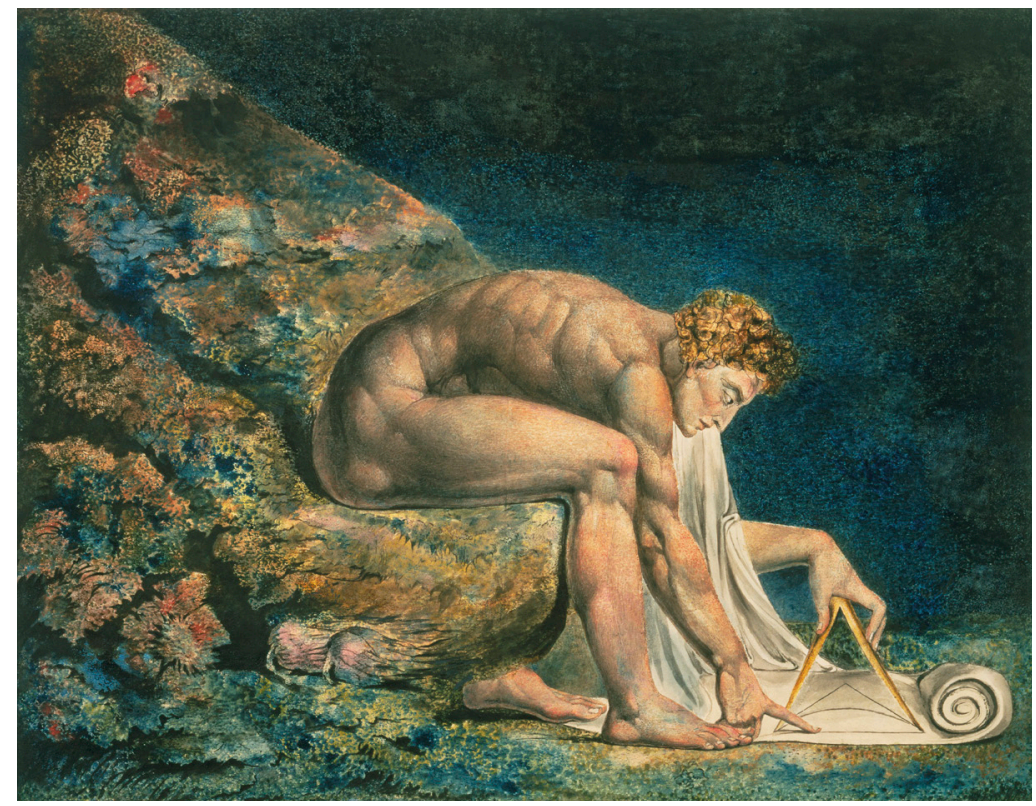

30 William Blake

Newton, 1795/c.1805 
into the new world of turbulence might be best approached through another Blake connection: his famous engraving of Isaac Newton, seated naked on a rock and leaning forward to ponder his own invention (the calculus), whose geometrical calculation appears in the diagram inscribed on the scroll rolling out from under his feet. (Figure 30) For the odd thing about this image is that it draws the great mathematician at the bottom of the sea. Because of slighting references to Newton elsewhere in Blake's oeuvre, there is tradition of interpreting this image ironically - as an illustration of a kind of mechanistic reasoning so absorbed in its own logic that it is deaf and blind to the sensuous world and, indeed, to the invisible medium of the spirit that supports us everywhere. But the idealisation of the naked figure as a kind of god is clearly against this view. W.J.T. Mitchell is surely right when he writes:

Everything we know about the 'doctrinal' Blake would lead us to expect the great codifier of Natural Law and reason to be presented as a patriarch with his writings inscribed in books and tablets. Blake presents him instead as a youthful, energetic scribe whose writings take the form (perhaps unintentionally ) of a prophecy. This is the Newton, not of 'single vision' and 'sleep', but the 'mighty Spirit from the land of Albion/ Nam'd Newton' who 'siez'd the Trump, \& blow'd the enormous blast!' that awakes the dead to judgment. Or, perhaps more accurately, it is the Newton whose 'single vision' is so intensely concentrated that it opens a vortex in his own closed universe, a figure of reason finding its own limit and opening into imagination. 65

As Mitchell intuits, Blake's Newton has threaded the passage between the 'closed universe' of reason and 'the opening to the horizon of the world' available to the imagination. He has passed from a closed universe characterised by universal laws that insist on the self-sameness of the physical world throughout time and space into an open world where to imagine what we know is to participate in the endless dialectic of becoming, to be pivoted between the present and future 
appearance of things, and hence to be the prophet of their unfolding. To achieve this transition is not simply to open a vortex: it is to pass successfully through its vortex in the new world, a task for the skilful diver. Traditionally, the vortex is a favoured figure of creativity, but this begs the question of how one becomes creative and manages the turbulence of changing the world. In the Vorticist manifesto, Ezra Pound called the vortex 'the locus of maximum energy', describing 'the artist DIRECTING a certain fluid force against circumstance' and the poem as 'the statement that has not yet spent itself in expression, but which is the most capable of expressing ... The DESIGN of the future in the grip of the human vortex.' 66 The artist of the vortex, then, is the one who successfully embodies the imagination: the 'expression' is the analog of his 'fluid force'. However, the verbal artist at least has to get his materials from somewhere, otherwise the vortex remains conceptual and inoperable. When the Portuguese writer Fernando Pessoa declared that his soul was a 'black maelstrom, a vast vertigo around a vacuum. (I am, he insists, 'the centre that doesn't exist except as a convention of geometry of the abyss; I am the nothingness around which this movement spins'), he also explained that round this black hole spin the membra disiecta of his life, 'houses, faces, books, boxes, musical refrains, and isolated syllables, in a sinister, bottomless whirl'. ${ }^{67}$

Obviously this is the style of Pound's Cantos, a helterskelter, cinematic presentation of 'scenes' of seemingly endless cultural and personal membra disiecta arranged into free-flowing bundles whose montage, in turn, recalls the way that Walter Benjamin organised the contents of the Arcades Project into twenty-six alphabetically designated 'convolutes' (literally 'bundles') or folders, thematically defined by various objects ... topics ... figures ... authors. ${ }^{68}$ Tomlins attributes this vortical system of organising matter to Benjamin's encounter with the author of the statement we quoted before ('It seems that there is some centre of the entire universe, and some general infinite vortex'): 'Benjamin developed the concept of constellation, which he also earlier called convolution, in the course of a multifaceted intellectual encounter with Leibniz.'69 In his translator's foreword to Gilles Deleuze's famous disquisition upon Leibniz, The Fold, Tom Conley calls 
Leibniz 'the first great philosopher of the pleat, of curves and twisting surfaces'. ${ }^{70}$ Convolution expresses time precisely in this fashion: folded, coiled, twisted; time not straight and sequential, endless extension, but sinuous, wound back on itself. Time, that is, expressed in the way that life itself is lived and recalled. Benjamin gives voice to the idea of convolution in his 1929 essay on Marcel Proust, whose massive memoir A la Recherche du Temps Perdu is famously launched from a fold of pastry - a 'petite madeleine - that is simultaneously a fold of time'. ${ }^{71}$ So it is no accident that the other inventor of the calculus, Newton, is, in Blake's engraving, working on the problem of calculating where the finite and the infinite meet and the area that the curve and the tangent then enclose or perhaps disclose.

More sedately and reflectively, the poet Paul Valery recognises the independent role the dynamics of the vortex play in imaginative formations. As the figure of the imagination the vortex represents the force of attraction or the power of identification from which poetry springs. Thus the 'secret [of poetic works] ... lies and can only lie in the relations they found - and were compelled to find-among things of which we cannot grasp the law of continuity'. ${ }^{72}$ In Valery's theory, 'The faculty of identification' ('there is nothing more powerful in the imaginative life') seizes upon its theme, whereupon 'The chosen object becomes as it were the centre of that life, a centre of ever multiplying associations, depending on whether the object is more or less complicated.' ${ }^{73}$ Here an initial centripetal force of attraction produces its counterforce, a centrifugal force that spreads out engulfing a growing region of matter and absorbing it into the world of the poem. This process of expansion and absorption should not be imagined as occurring in flat space, as if the poet was engaged in a campaign of territorial conquest. It occurs on a Riemannian surface, for the poetry of the Symbolists, and of Mallarmé in particular, does not become clearer as it expands. On the contrary, it folds more and more into itself, revelation being inseparable from re-veiling. The Symbolist poem is a genuine act of world-making, one that takes into account the rondure of this worldly reality. Think of each image in a Symbolist poem as a plate in a coat of chain mail; and imagine the coat 
as spherical. Each image stands at an angle to its received definition, and occupies its own plane, so that neighbouring images have distinct horizons. The logic of the poem can only be grasped by navigating it: there is no end to its horizons, and the reader-sailor never achieves a circumnavigation that produces a complete picture. Instead the path is helical, endless, continuously unfolding across discontinuities.

The artist of the transition steers into the maelstrom, mapping it as well as navigating it. The vortex is not only what is imagined: it is the structure of the imagination itself. Pessoa may compare the state of his soul to a 'nothingness' but it clearly has a structure: it is a hollow, a conical involute 'around which this movement spins', and the form the hollow assumes is the offspring of the physical laws governing the unstable equilibrium of the whirling. The term 'involute' comes from Thomas De Quincey's account of the nature of memory in his essay Suspiria in profundis. ${ }^{74}$ Pessoa's state of 'nothingness' recalls the one De Quincey describes when what he calls 'the organising principles' fail: 'In parts and fractions eternal creations are carried on, but the nexus is wanting, and life and the central principle, which should bind together all the parts at the centre, with all its radiations to the circumference, are wanting. Infinite incoherence, ropes of sand, gloomy incapacity of vital persuasion by some one plastic principle ...' ${ }^{75}$ When they work, though, the 'organising principles' find a pattern in mental data 'which by pure accident have consecutively occupied the roll'. ${ }^{76}$ De Quincey's parchment, and the palimpsestic traces it bears, is imagined as a roll or convolute in Benjamin's sense and, when they succeed, the 'organising principles' produce 'involutes' - 'far more of our deepest thoughts and feelings pass to us through perplexed combinations of concrete objects, pass to us as involutes (if I may coin that word) in compound experiences incapable of being disentangled, than ever reach us directly, and in their own abstract states'. ${ }^{77}$

The term 'involute' itself comes from the technical vocabulary of what used to be called conchology, the science of shell classification. Early nineteenth-century handbooks of conchology describe an astonishing variety of shell forms; and the equally astonishing poetic inventiveness of the names used to classify these is remarkable for its attempt to capture 
the architecture of the hollow itself, the winding internal volume of the shell rather than its external appearance. It is interesting that the author of Descent into the Maelstrom also arranged the contents of The Conchologist's First Book. In his introduction, Poe makes the point that shells have a privileged place in geognosy because they bridge the organic and inorganic worlds, belonging equally to biology and geology. His lexicon evokes an architecture of the hollow: 'Pillar, or columella, is that process which runs through the centre of the shell in the inside from the base to the apex of most univalve shell, and appears to be the support of the spire.'78 The 'Spire consists of all the whorls of the shell, except the lower one ... termed the body of the shell'. ${ }^{79}$ 'Whorl is one of the wreaths or volutions of the shell.'80 An 'involuted spire' refers to 'those shells which have their whorls, or wreaths, concealed in the inside of the first whorl or body, as in some of the Nautili and Cypraea'. 81

It has occurred to me that De Quincey was critically selective in his choice of the term 'involute', that he wanted to distinguish the way his imagination was structured from the topology it might exhibit in other individuals. In fact, you could imagine different mental structures of memory resembling different species of the five genera of columellaria - which, in general, exhibit a 'Thick, turbinated, with a short obtuse spire.'82 The 'first whorls of the spire' of the genus Voluta are 'rounded into a teat'; and 'the columellar edge' is 'garnished with large folds more or less oblique, and slightly varying in number with age'. ${ }^{83}$ The genus Volvaria has a shell that is 'Cylindrical, convolute; spire obsolete or concealed; aperture narrow, extending the whole length of the shell ...'84 The shell of the Cyprea genus of the Convoluta family is 'Oval, convex, very smooth, involute' and the 'spire entirely posterior ...'85 (The glossary defines 'involute' as 'without a spire'.) ${ }^{86}$ Of this, 118 species are recorded. In any case, whatever the merit of this fantasy, it reminds us that when Valery imagines 'the faculty of identification' encasing the 'centre of that life' in 'ever multiplying associations', ${ }^{87}$ he describes a distinct and fateful architecture that recalls the formation of shells. 'The majority of gastropod species (over 90 per cent) have dextral (right-handed) shells in their coiling, but a small minority of 
species and genera are virtually always sinistral (left-handed). A very few species (for example Amphidromus perversus) show an even mixture of dextral and sinistral individuals.' 88 Perhaps in a comparable way poems also exhibit chirality, the 'handedness' of their volume integral to the unfolding of the sense.

In this case the hollow of the shell is 'the Trump' the prophet blows and the sound of 'the enormous blast' will be an atmospheric turbulence that resounds with the physical volume whence it emanates. While the generation of audible turbulence, that is, noise, in the vocal tract is necessary for the production of fricatives, the fricative release of affricates and the burst of stops, audible turbulence may also be associated with the production of vowels and sonorants in certain conditions. There is some degree of low-level air flow turbulence even for the most open of speech sounds - something we might perceive as breathiness. The fundamental identity of physiology, pneumatology and psychology has suggested to Bachelard the idea that, ultimately, breath patterns structure the world, a notion analogous to Descartes' theory of vortices. In a meditation on the aerial imagination, Bachelard refers circumspectly to Charles Nodier's theory of 'mimologism' (advanced in his Critique of French Dictionaries, 1828), according to which the origin of a word resides in 'the whole group of oral and respiratory conditions that must be discovered by physiognomic imitation of facial expressions as we speak'. ${ }^{89}$ The etymologist of the vocal organs discovers the phonetic history of a word recapitulated each time it is sounded out. Bachelard locates the mimicry elsewhere, not in the act of articulation but in the 'mimologism of total breathing' $.90 \mathrm{On}$ this basis, the aerial imagination manifests itself in a kind of breath speech - 'Let us make no noise but our breathing, taking only shallow breaths - let us imagine only those words that form as we breathe'. ${ }^{91}$ 'The pneumatology of lines' dictated by breath 'would be expressed as a volume' 92 - an idea Mary Le Cron Foster takes up when she speculates that language may have originated in a process 'by means of which states and movements in space [were] translated into spatiosonant, articulatory counterparts'. ${ }^{93}$ Instead of listening and repeating the numbers lisped by nature, the first speakers, according to Foster, physically imitated the valleys, paths, groves, rocks 
and grottos. Shaping mouth, lips, tongue and vocal tract in imitation of external states and movements, they produced the vocal equivalents of those places.

Did you think that the diver's training consisted of successive plunges into the millstream of life, that his and her skills were the sole result of learning to be out of his depth? These skills the anchorites ${ }^{94}$ of the deep learn 'on the job': no, the question addressed to her is curricular. What is the mental equipment the diver needs to thread the eye of the whirlpool and plumb the depths? It is first and foremost an education in the poetics of the vortex, whose creative lineaments the diver follows as winding himself into its hollow he unlocks the door of the unknown. Of course what is offered here, fragments of passages from Poe, Valery, Pessoa, Pound and others (whirled together perhaps for the first time) can only be the membra disiecta of such a program, but they indicate at least that such a literature exists, albeit neglected. Nor, of course, is the diver's upperworldly education conducted entirely at a school desk. It whirls out to embrace associatively widening gyres of experience, a growing involvement in the world. A later skill in collecting shells from the seabed, say, is preceded by an eye for such things above. The Roman building tradition, and its selfconscious intensification in the architecture of Alberti and Michelangelo, uses the shell as a metonymy of the building itself. The scallop is one half of the cupola; it is the porch and the preferred peripheral decoration of doorways; the scallop crowns windows and is imprinted under eaves. As the type of the shell, it encrusts the temples of the upperworld in a precious casement of marine history. To enter these places is to swim into a dark, richly coralled grotto - the baroque interior is similar to the impression a diver has on the Barrier Reef.

Shells are symbols of vorticality ('vortex' is etymologically identical with 'vertex'): their recovery demands the depth psychology of a diver. Although shells pile up and form heaps, they also suggest vortical staircases, openings, doublings and returns: there is a difference between the deposited midden and the spirit in which the diver collects shell fish, sponges and other wealth of the underwater. The diver is the figure associated with the cosmos of chalk: he plunges into the depths and in the process provides a model of De Quincey's mental 
deep sea dive through which the strangest data are brought together and mysteriously connected. Jacques Cousteau's descriptions of the hallucinations that divers suffer is similar to what happens to the 'facts' in the whirling recovery that De Quincey compares to the structure of the involute. ${ }^{95}$ The diver is the aesthete who, like the English art writer Adrian Stokes, attempts to derive the surface incrustations of the fifteenth-century Italian low relief sculptors from the deep geological history of the materials into which they cut. ${ }^{96}$ (There is another association here, which Stokes didn't notice, between scallop, scalpel and sculpture - the sculptor is a kind of human mollusc who constructs around him an exoskeleton of ideal forms.) The diver goes down: if the twinned shells of the cockle shell resemble the labia majora, then he can go down sexually, but what counts is the larger aphrodisiac of salt and the plunge into deeper waters.

\section{V}

It is important to emphasise the reasonableness - the worldiness - of the principles informing the art of transition. Turbulence, and its face, the vortex, have usually been associated with madness, a classification that also has its counterpart in geographical pathology. When the spirit held dominion over his body, Swedenborg wrote, the body 'flew up, in a manner, and hid itself in an infinitude, as a centre. There was love itself. And it seems as if it extended around therefrom, and then down again; thus, by an incomprehensible circle, from the centre, which was love, around, and so thither again. ${ }^{97}$ Inaugurated into a higher life, Swedenborg 'was bandaged and wrapped in wonderful and indescribable courses of circles'. ${ }^{98}$ But this was the man that Kant thought typified a disease of the soul, a certain 'irrational fanaticism (Schwärmerei) that was then thought [1790] to be infecting the European mentality. ${ }^{99}$ People who interested themselves in mesmerism, clairvoyance, ESP and the like had 'crossed the line'- 'just as if a man who crosses the equator for the first time were in danger of losing his understanding'. ${ }^{100}$ But it is not necessary to prove that madness has its cultural logic or that reason floats on an unconscious sea: in poetic geography, Blake's vortices and the turbulence of the infinite that they 
manifest belong to the physics of rondure. Australia, Hades, the hollow, all spiralling traces forming in the wake of passage are the unwrappings of the one infinite plane. The topology of the twist applies equally to the organisation of sociability and the elemental architecture of the world.

The archipelago that characterises the new geography reflects an oceanic consciousness, an ease with the ebb and flow of relations and a competence to traverse the deep. I do not know why Blake demonised Newton: if there was a problem with Newton's metaphysics (as opposed to his physics) it was due to its landlubberly delegation of oceans and islands to a secondary place in the spiritual universe - and this, to judge from the relative absence of 'Ocean' from Blake's otherwise encyclopaedic mythography, was a bias the poet shared. In this sense, just as Milton was of the devil's party without knowing it, so Blake was of Newton's party without admitting it. Blake wrote of his 'three years Slumber on the banks of the Ocean'; Newton used a similar figure to sum up his life's work: 'I do not know what I may appear to the world, but to myself I seem to have been only like a boy playing on the seashore, and diverting myself now and then finding a smoother pebble or a prettier shell than ordinary, whilst the great ocean of truth lay all undiscovered before me.'101 Perhaps we should say that both were of the Ocean's party without knowing it. However, their spiritual geographies remain landlocked. Thus, developing the proposition that 'The whole world natural consisting of heaven \& earth signifies ... whole world politique consisting of thrones \& people', Newton explains, 'In earth the dry land \& congregated waters, (as a sea a river a flood) are put for the peoples of several regions nations \& dominions', describing 'Mountains \& Islands' as being 'for the cities of the earth \& sea politique with their territories \& dominions'. ${ }^{102}$ There is no suggestion here of a political economy derived from the fluidity of the sea.

Blake, of course, had a far more ramified mythological geology, which, if I understand it, remained resolutely preHuttonian. Where Hutton derived the present distribution and topography of the earth's land forms from forces of upthrust, erosion and renewal, Blake adhered to the older, Neptunian (or Biblical) theory of the land's formation in 
which the dry surface of the world originally floated on top of a subterranean ocean. Hence, in Burnet's Sacred Theory before the Deluge the surface floated on the waters and was composed of particles aggregating on the oil surface to form a crust - but after a time it began 'to crack and open in fissures...' 103 This could be easily be allegorised:

The crimes of mankind had for some time been preparing to draw down the wrath of heaven; and they at length induced the Deity to defer repairing those breaches of nature. Thus the chasms of the earth everyday became wider, and, at length, they penetrated to the great abyss of waters, and the whole earth in a manner fell in. Then ensued a total disorder in the uniform beauty of the first creation. ${ }^{104}$

On this thesis the Flood (Deluge) was due to a vast migration of waters of the great abyss (mainly identified with the Pacific) and the present appearance of the globe is due to our 'fall' into the abyss: 'the oceans and the seas are still a part of the ancient abyss that have not had a place to return to. Islands and rocks are fragments of the earth's former crust; kingdoms and continents are larger masses of its broken substance; and all the inequalities that are to be found on the surface of the present earth, are owing to the accidental confusion into which both earth and waters were the thrown...' 105

This raises two questions: what was the 'uniform beauty' of the First Creation like? Blomfield quotes Buffon: 'Though the inequalities upon the surface of the earth may be considered a deformity in its figure, they are absolutely necessary to vegetation and animal life ... ${ }^{106}$ Similarly a Mr Kirwan is quoted approvingly for saying that mountains are providentially designed-convincing proofs of wisdom and beneficence'. ${ }^{107}$ In this case the sea only matters as a leveller, an agent of moral renewal and regulation: the Deluge myth suggests that mountains (islands and continents) are produced negatively, not by Huttonian upthrust but by the collapse of the uniform surface into the abyss, producing a displacement of subterranean waters and a disastrous rise in the sea's level. The uplift of the water produces the conditions of the second creation where 
peoples and places are fragmented, split apart and subject to local variation. It is the situation lamented at the beginning of the Medea ${ }^{108}$ but it is also quite consistent with the imperial rationalisation of colonisation, for where all are primordially displaced the rational redistribution of human kind to redeem the 'waste' is an act of redemption, kindness, replacement and progress. In this scenario the levels of the sea signify a Paradisal uniformity but also the apocalyptic punishment of human evil.

In a similar vein, Blake thought that the British Isles were fragments of the ancient Albion qua Atlantis, inundated during the Flood:

The fall of Albion included a deluge in which the centre of Atlantis was overwhelmed and only the fragments of the British isles were left. The settlement of America by the English and revolt of America against the dead hand of English tyranny is therefore the dawn of a new age in which Atlantis begins to appear above the waves. In the meantime England still exists in the spiritual world as Atlantis, and Blake's engraved poems are on its mountains. ${ }^{109}$

According to this vision, postlapsarians inhabit an archipelago bordered on every part by the abyss. Thus displaced the balance of the displaced water had collected into water bodies of which the greatest modern survival is the Pacific Ocean. Newton dived to the bottom of the sea to find the solid ground of reason when, with the advantage of Blake's mythopoetic fantasy, he should have been looking on the mountain tops for the original state of things. But it is obvious that the abyssal archipelago sketched here is different from the archipelago of the new cosmos described earlier, not only in its origin but in its internal and external isolation. The new Atlantis is an archipelago from the start, a distribution of forces, a field of actual relations and potential exchanges and transformations.

What, exactly, is Newton drawing with his dividers? It is a question that cannot be answered correctly without also asking: what does Blake draw Newton drawing? Thus, in Blake's perspective, Newton's perfect circle looks like a flattened 
circle or oval. Newton may think it is a purely logical form, an immaterial concept corresponding exactly to a mathematical equation, but, inscribed within the turbulent 'vortex' of infinity, its egocentricity is a sign that it belongs to 'those sciences which have enlarged the limits of the empire of man over the external world' but which 'for want of the poetical faculty' have 'proportionally circumscribed those of the internal world'. So Blake's poetical faculty enables him to circumscribe Newton, and by depicting him at the bottom of the sea to suggest that, while his 'science' enslaves the elements, he himself remains the slave of his own calculations.

In this convoluted reflective perspective, Newton's circle becomes a version of the 'mundane shell': 'The world of time and space in the egg-shaped Mundane Shell is a symbolic representation of the perfect circle of the eternal Sun.'110 The mistake is to suppose the fallen image can represent the divine truth, the finite the infinite - to suppose that the egg is a circle, the ovoid a perfect round. Still, perhaps Newton knew this: drawing his figure on a scroll, itself still partly rolled up, he might anticipate new geometries yet hidden, the higher calculus of turbulence. After all, I suppose that drawing a circle under water would produce a warped figure.

To go back to Blake and Newton on their respective beaches: Playing and sleeping, experimentally rearranging or handing over rearrangement to the unconscious, as occurred in the composition of 'Milton'. Either way ideas come to them on the shore, on the edge of the known - where the Ocean stands for the unknown. The strand is where one is stranded, imprisoned, but in touch with mysterious strands, it is the threshold of the labyrinth, it is where, in Keats's mythopoeia, conventional language gives out and the question is posed: 'Are there not other regions than this isle?'111 Keats conducts a subtle meditation on the contrasting homes represented by land and sea: when he speaks of the 'deep blue' as representing the Ocean's 'Nativeness', he defines the unknown region in terms of its reflection, the blue sky: 'What strange powers/ Has thou, as a mere shadow!' 112 Keats explicitly identifies the environmental beyond with the afterlife when 'on the shore/ Of the wide world I stand alone, and think/ Till love and fame to nothingness do sink.'113 Thought or intellection cuts both 
ways: it confirms our insignificance-Newton's sense of being but a little boy-but it also produces a sense of detachment that is intolerable, something like the dizzying vertigo of nothingness experienced by Pessoa, and, in reaction, a desire of connection that is irresistible, dynamically pretty much as the waves repeatedly withdraw only to renew their battery on the land.

So the first vortex, psychologically speaking, is the second birth through which the biological human is initiated into the spiritual human, an event that occurs in adolescence and may be associated with sexual self-awareness but is more profoundly the birth of the double consciousness, the translation of the path into the spiral. Vico falls from a ladder in his father's library and is knocked out, but he attributes his future calling to the acuity of wit his concussion induced.114 Swedenborg experienced dizziness or deliquium - 'In a dream a roaring wind picked him up and threw him on his face ...'115 preliminary to twenty-five years of daily intercourse with angels. Deliquium? To absorb moisture from the air. That is, the usually dry man became humid, like one walking into the water. More famously, as we saw, the author of vortices, but more influentially of geometrical reasoning, Descartes, arrived at his famous formulation through a storm of perturbation - and one remembers that another term for agoraphobia is Platzschwindel, dizziness in open spaces. Further, in another dream associated with his intellectual breakthrough, Descartes imagined himself submerged in a turbulent stream, and panic-stricken, made as best he could for the bank, and shaking off the water, set out in a straight line, on the grounds that it must eventually lead somewhere.

The humid man is not, like Descartes, out of his depth: he learns to swim, to dive: the height of his ascent will be proportioned to the depth of his descent. He will be an examiner of reefs and learn to hold his breath: the writer who ducks under horizons, as opposed to descending in a chariot from the sky beyond, learns to hold her breath. This is dramatic: after all, the whole of theatre occurs in the instant between two breaths, it is like a suspended swoon, such as one might experience waiting for a loved one at the station. In any case the traveller who comes out of the vortex of immersion 
is neither a slumberer nor a little boy playing; the fate of Virgil's steersman, particularly as it is interpreted by the poet of diving, Giuseppe Ungaretti, is to remain too fixed on his destination. ${ }^{116}$ In a sense he falls asleep at the wheel because, perhaps like Blake's Newton, he fails to take account of Poseidon's moodiness. He is not up for the artistry of complex change. Because of his obdurateness he is turned into a rocky promontory, whereas the Orphic investigator of Ungaretti's genius glimpses remote ages through the pellucid water and manages the task of carrying them forward into the constitution of the present. The humid traveller enjoys liquidity because he navigates vortices whose communication is based on momentary disequilibriums, inherent instabilities that propel him from one eddy to the next. It is notable that Blake regarded the stars as fragments of the primal sun, astronomical equivalents of Orpheus' severed and divided tongue but Newton explained their motions without regretting it. Newton did something else which recommends him to travellers in the Pacific, who adapt to the dark: he attributed their scintillations to the atmosphere: 'For the Air through which we look upon the Stars, is in a perpetual Tremor; as may be seen by the tremulous Motion of Shadows cast from high Towers.' 117

Atmospheric turbulence transforms lunar and solar rays into a tremulous motion of shadows. By day this tremor is the sparkling of the waves - Keats describes 'Blue' as 'the life of waters'; 'Ocean/ And all its vassal streams, pools numberless,/ May rage, and foam, and fret, but never can/ Subside, if not to dark blue nativeness.' 118 Is it possible to dwell in this Atlantic where all nostalgia for the ground has to be given up? It is a mistake to associate the ocean with oblivion, to imagine it solely in terms of the abysses it conceals and its inventories of shipwrecks. It lifts up as well as brings down; and its vital turbulence, ceaselessly active even when it sleeps, brings us into the arms of the future we can never inhabit more surely than in human prophecy. As perhaps the greatest poet of the maelstrom, Herman Melville, reflected:

There is, one knows not what sweet mystery about this sea, whose gently awful stirrings seems to speak of some hidden soul beneath; like those fabled undulations of the 


\section{Ephesian sod over the buried Evangelist St John. And meet it is, that over these sea-pastures, wide-rolling watery prairies and Potters' Fields of all four continents, the waves should rise and fall, and ebb and flow unceasingly; for here, millions of mixed shades and shadows, drowned dreams, somnambulisms, reveries; all that we call lives and souls, lie dreaming, dreaming, still; tossing like slumberers in their beds; the ever-rolling waves but made so by their restlessness. ${ }^{119}$}

\section{Notes}

W. Blake, 'Milton', Book The First, 15: 21-5 in Complete Writings, ed. G. Keynes (Oxford: Oxford University Press, 1969), 497. For discussion of this and related passages, see Mark Greenberg, 'Blake’s Vortex', Colby Quarterly 14, no. 4 (1978): 198-212. William Blake, 'Milton', Book The First, 15: 32-3.

3 From Felpham, a seaside town near Bognor Regis, where he lived between 1800 and 1803 , Blake write to his friend Thomas Butts: 'none can know the Spiritual Acts of my three years Slumber on the banks of the Ocean unless he has seen them in the Spirit or unless he should read My Long Poem descriptive of those Acts'. (Blake, Complete Writings, 823.) On the question of whether 'Vala or the Four Zoas' or 'Milton' is referred to here, see S. Goldsmith, Blake's Agitation: Criticism and the Emotions (Baltimore, MA: Johns Hopkins University Press, 2013), 114 .

M. C. Percival, William Blake's Circle of Destiny (New York: Columbia University Press, 1938), 148.

5 And also erotic in the largest sense: Swedenborg, Blake's sometime master, writes of 'the divine love, radiating from the lord as the Sun ...', E. Swedenborg, The True Christian Religion (London: Dent, 1933, 420). With dogmatic straightforwardness, Swedenborg declares that 'the heat and light proceeding from the Lord as a Sun contain all the infinities of the Lord', (420) a fact that the creative imagination recognises when, as celebrated in Blake's famous 'Auguries of Innocence', it discerns 'infinities' within 'simple phenomena' (420-1).

6 'the threefold division [between mind, psyche, and spirit] has collapsed into two, because soul has become identified with spirit. This happens because we are materialists, so that everything that is not physical and body is one undifferentiated cloud; or it happens because we are Christians', J. Hillman, Re-Visioning Psychology (New York: Harper \& Row, 1975), 68.

7 P. B. Shelley, 'A Defence of Poetry' in The Selected Poetry and Prose of Shelley (Ware, Herts: Wordsworth Editions, 1994), 635-60, 655.

8 Although cognate with words signifying 'East', Auster becomes identified in Roman usage with the south wind. Strictly speaking, 'Australia' refers to a realm further to the south and east of where Australia lies.

9 Sandra Saunders, They've got God on Their Side, in 'Deadly in between Heaven and Hell' exhibition, Tandanya National Aboriginal Cultural Institute, Adelaide, March 2012. 
10 'Everything under Creation is represented in the soil and in the stars. Everything has two witnesses, one on earth and one in the sky.' Properly conducted life conforms to the lessons drawn from the stories discerned in the order of the stars: 'Everything is represented in the ground and in the sky'. (D. Mowaljarli and J. Malnic, Yorro Yorro: Everything Standing Up Alive (Broome, WA: Magabala Books, 200, 5 .

11 A. S. Gourlay, An Emergency Online Glossary of Terms, Names, and Concepts in Blake, at <http://www.blakearchive.org/exist/blake/archive/glossary.xq?chunk. id=glossary\&toc.depth $=1 \&$ toc $. i d=0>$.

R. V. Billigheimer, 'The eighth eye: prophetic vision in Blake's poetry and design', Colby Quarterly 22, no. 2 (June 198): 93-110, 94.

13 K. Raine, Blake and Tradition (New York: Routledge and Kegan Paul, 1969), 85.

14 See note 1 above.

15 D. Chow, 'Moon's reflected "earthshine" may aid Search for alien life', 29 February2012, at <http://www.space.com/14712-earthshine-moon-light-alien-life. html>.

16 Ludmilla Kolokolova et al., 'Astrobiological remote sensing with circular polarization', in Polarimetric Detection: Characterisation and Remote Sensing, eds M.I. Mishchenko et al. (Dordrecht: Springer, 2010), 278.

17 T.M. Gledhill et al., 'Astro-biological signatures: prospects for the detection of non-terrestrial biological material', at <http://uhra.herts.ac.uk/bitstream/ handle/2299/1690/901878.pdf?sequence $=113>$.

18 Patrick Frank et al., 'On one hand but not the other: the challenge of the origin and survival of homochirality in prebiotic chemistry', in Chemistry for the $21^{\text {st }}$ Century, eds E. Keinan and I. Schecter (Weinheim: Wiley, 2001),175-208, 176.

19 S. Bagnulo et al., 'The earth as benchmark: spectro-polarietry unveils strong bio-signatures', see the Smithsonian/NASA Astrophysics Data System at $<$ http:// adsabs.harvard.edu/abs/2012EGUGA..1412224B $>$.

20 A. von Humboldt, Cosmos, A Sketch of the Physical Description of the Universe, vol. 1, trans. E.C. Otté (Baltimore: The Johns Hopkins Press, 1997), 33.

21 Blake, 'Milton', Book The First, 15: 29.

22 Swedenborg, The True Christian Religion, 91.

23 Ibid., 90.

24 S. Rosen, Metaphysics in Ordinary Language (New Haven: Yale University Press, 1999), 23.

25 Known as the first Olympian Dream. In the period leading up to his first Olympian dream, Descartes 'found himself caught in a continual contention in which he could find diversion neither in walking nor in human society', J. R. Cole, The Olympian Dreams and Youthful Rebellion of René Descartes (Urbana: University of Illinois Press, 1992), 32.

26 Striking visualisations of his whirlpools of matter can be found on the web. A particularly beautiful and widely reproduced diagram is from Descartes' Principia Philosophiae, Amsterdam, 1653, 134.

27 Writing in 1676. See Christia Mercer, Leibniz's Metaphysics: Its Origins and Development (Cambridge: Cambridge University Press, 2004), 415 for this passage and discussion.

28 A. C. Swinburne, 'The Triumph of Time', at <http://www.poetryfoundation.org/ poem/174574>

29 William Blake, 'Jerusalem', Plate 18, 2-3. Complete Writings, 640.

30 Phaedo, 107a-115a.

31 Cornford, Principium Sapientiae (New York: Harper \& Row, 1952 [1912]), 194 n.1.

32 M. T. Varro, Varro on the Latin Language 2 vols, trans. R.G. Hunt (London: Heinemann, 1947), vol. 1, 17. 
66

Varro, vol. 1, 19.

Varro, vol.1, 19.

J. Carcopino, La Basilique Pythagorienne de la Porte Majeure (Paris, 1926), 288.

H. Baker, Persephone's Cave (Athens, 1979), 121.

A. Carnoy Dictionnaire Etymologique du Proto Indo-Europeen (Louvain: Institute Orientaliste, 1955), 174.

Hillman, 109.

W. Blake, 'Milton', Book The First, 15: 3-31.

S. F. Damon, A Blake Dictionary: The Ideas and Symbols of William Blake (New York: Dutton, 1971), 369.

Ibid., 69.

Ibid., 247.

Giorgio Agamben, The Time That Remains, A Commentary on the Letter to the Romans, trans. Patricia Dailey (Stanford: Stanford University Press, 2005), 137. Rosen, 16.

Ibid., 30.

Ibid., 31 .

Ibid.

Ibid.

Ibid., 32

Hannah Arendt, 'What remains? The language remains' in The Portable Hannah Arendt, ed. P. Baehr (London: Penguin, 2000), 21

Predrag Matvejevic, Mediterranean: A Cultural Landscape, trans. M.H. Heim (Berkeley: University of California Press, 1999),163.

Giorgio de Santillana and Hertha von Dechend, Hamlet's Mill, Boston: Nonpareil, 2005, 146.

Thomas Belt, The Naturalist in Nicaragua (London: J.M. Dent, 1928), 233. Ibid.

P. Carter, The Lie of the Land (London: Faber \& Faber, 1996).

T.G.H. Strehlow, Songs of Central Australia (Sydney: Angus \& Robertson, 1971), 444 .

M. Serres, 'The Origin of Language: Biology, Information Theory, \&

Thermodynamics', in Hermes; Literature, Science, Philosophy, ed. J. V. Harari and David F. Bell (Baltimore: Johns Hopkins University Press, 1982). At <http:// mysite.pratt.edu/ arch543p/readings/origin_of_language.html> .

Matvejevic, 17.

K. Siivonen, 'An archipelago of identities', presentation at BSRS, Mare Balicum, University of Turku, 17 October 2008, 1-43, 3.

Laurence Durrell, Reflections on a Marine Venus (London: Faber \& Faber, 1953), 15 Siivonen, 14.

M. Polo, The Travels of Marco Polo (London: J.M. Dent, 1936), 329. The number varies in different manuscripts. See $<$ https://www.mail-archive.com/maphist@ geo.uu.nl/msgo1475.html $>$. von Humboldt .

See A. P. Burnett, The Art of Bacchylides (Cambridge, Mass: Harvard University Press, 1985), chapter 2.

65 W.J.T. Mitchell, Picture Theory: Essays on Verbal and Visual Representation (Chicago: University of Chicago Press, 1994), 136.

Blast: Review of the Great English Vortex, no. 1 (1914)

F. Pessoa, The Book of Disquiet, trans. Alfred Mac Adam (New York: Pantheon Books, 1991), 19.

68 See entry for Walter Benjamin, Stanford Encyclopedia of Philosophy at $<$ http:// plato.stanford.edu/entries/benjamin/>. 
69 C. Tomlins, 'Revolutionary justice in Brecht, Conrad and Blake', Law and Literature 21, no. 2, 185-213 (2009), 188.

70 T. Conley, 'Foreword', G. Deleuze, The Fold, trans. T. Conley (London: Continuum, 2003), xii.

71 At $<$ politicaltheory.wustl.edu/workshop_papers/Tomlins, Revolutionary\%20 Justice.pdf $>$

72 Paul Valery, 'Introduction to the method of Leonardo da Vinci' and 'Poetry and abstract thought', in An Anthology, selected by J. R. Lawler from The Collected Works of Paul Valéry, ed. J. Mathews (London: Routledge, 1977), 34.

73 Valery, 'Introduction to the method of Leonardo da Vinci', 34.

74 Thomas De Quincey, 'Suspiria in Profundis', Essays (London: Ward, Lock and Co, 1886), $137 \mathrm{ff}$.

75 Ibid., 103.

76 Ibid.

77 Ibid., 104.

78 E. A. Poe, The Conchologist's First Book (New York: Haswell, Barrington and Haswell, 1839), 16.

79 Ibid.

80 Ibid., 17.

81 Ibid.

82 Ibid., 144 .

83 Ibid., 146.

84 Ibid., 147.

85 Ibid., 18.

86 Ibid., 159.

87 Valery.

88 See <http://en.wikipedia.org/wiki/Sinistral_and_dextral >.

89 G. Bachelard, Air and Dreams, trans. E. R. Farrell and C.F. Farrell (Dallas: Dallas Institute, 1988), 241.

90 Ibid., 242.

91 Ibid., 241.

92 Ibid., 242.

93 M. Le Cron Foster, 'The symbolic structure of primordial language', in Human Evolution: Biosocial Perspectives, ed. S.L. Washburn and E.R. McCown (Menlo Park, Calif: Benjamin/Cummings 1978), 117.

94 With reference to a somewhat vortical radio work, P. Carter, 'Underworlds of Jean du Chas', a radio work inspired by Samuel Beckett's imaginary art movement 'Concentrisme'.) 'HOLLOW: He spoke to me. He said: Spit the diddy, anchorites, cast anchor from the breast, dear friends. We have rites below to perform, I have prepared the abyss. Cup the crucible, mateys, advancing towards the edge. Don the goggles and the bit (qualified hypnogogues will help). Then like a harpoon plunge, my crystals, towards the centre of the fire. $\mathrm{O}$ blessed is the man who makes the perfect rip and leaves no ripple in his wake; his soul is shared with the universe'.

95 J. Y. Cousteau, The Silent World (London, Hamish Hamilton, 1953).

96 A. Stokes, 'The pleasures of limestone: a geological medley', chapter 2 of Stones of Rimini (1934) in The Critical Writings of Adrian Stokes 3 vols, ed. L. Gowing (London: Thames and Hudson, 1978), vol. 1, 190-204.

97 E. Swedenborg, Swedenborg's Journal of Dreams, trans. J.J.G. Wilkinson (New York: Swedenborg Foundation, 1977), 28.

98 Swedenborg, Swedenborg's Journal of Dreams, 13.

99 Robert E. Butts, Kant and the Double Government Methodology (Dordrecht: Reidel Publishing Company, 1984), 11-12. 
100 I. Kant, Anthropology from a Pragmatic Point of View, trans. H.H. Rudnick (Carbondale: Southern Illinois University Press, 1978)

101 P. N. Moore, The End of History, Messiah Conspiracy (np: Ramshead Press, 1996), 518.

102 See <www.newtonproject.sussex.ac.uk/view/texts/normalized/THEMoooo5>.

103 E. Blomfield, A General View of the World, Geographical, Historical and

Philosophical, in 2 vols, (Bungay: C. Brightey \& T. Kinnersley), vol 1, 129.

104 Ibid.

105 Ibid.,129-30.

106 Ibid., 99.

107 Kirwan in Ibid.

108 See opening speech of Euripides' Medea: 'I wish they'd never chopped the pine trees down/ in those mountain forests up on Pelion,/ to make oars for the hands of those great men/ who set off, on Pelias' orders,/ to fetch the golden fleece: $<$ https://records.viu.ca/ johnstoi/euripides/medea.htm $>$ lines 5-9.

109 N. Frye, Fearful Symmetry: A Study of William Blake (Toronto: University of Toronto Press, 2004), 129.

110 R. Billigheimer, 'Conflict and conquest: creation, emanation and the female in William Blake's mythology', Modern Language Studies 30, no. 1.

111 J. Keats, 'Hyperion', Poetical Works (Oxford: Oxford University Press, 1970).

112 J. Keats, 'Written in Answer to a Sonnet Ending Thus', Sonnets IX, Poetical Works, 367.

113 J. Keats, 'Sonnets', VII, Poetical Works, 13-14, Poetical Works, 366.

114 See D. P. Verene, 'Giambattista Vico', in A Companion to Early Modern Philosophy, ed. S. Nadler (Oxford: Blackwell, 2002), 564.

115 B. Worcester, Swedenborg: Harbinger of the New Age of the Christian Church (Philadelpha: J.B. Lippincott, 1912), 167.

116 G. Ungaretti, 'Palinurus', La Terra Promessa, 1950.

117 I. Newton, Opticks, or a Treatise of the Reflections, Refractions, Inflections and Colours of Light, [1730] New York: Dover Publications, 1952), 110.

118 See note 114 above.

119 H. Melville, Moby Dick. Melville's vorticism is explicitly designed to disprove the pantheistic optimism of the Transcendentalists. 